\title{
Determination of the Shortest Path Using the Ant Colony Optimization (ACO) Algorithm Approach
}

\author{
Hengki Tamando Sihotang* \\ Teknik Informatika, STMIK Pelita Nusantara \\ Jln. Iskandar Muda No. 1 Medan, Sumatera Utara 20551, Indonesia \\ hengki_tamando@yahoo.com
}

Received: $2^{\text {th }}$ November 2020/ Revised: $12^{\text {th }}$ April 2021/ Accepted: $13^{\text {th }}$ April 2021

\begin{abstract}
How to Cite: Sihotang, H. T. (2021). Determination of the Shortest Path Using the Ant Colony Optimization (ACO) Algorithm Approach. ComTech: Computer, Mathematics and Engineering Applications, 12(2), 123-133. https://doi.org/10.21512/comtech.v12i2.7964
\end{abstract}

\begin{abstract}
Distribution is one of the essential activities in business because it determines the price of products or goods in the market. So, choosing the shortest path is considered one of the most important things in business, especially distributors. PT Everbright, one of the business actors engaged in the manufacture of batteries and as the main distributor, hopes that the distribution of goods to have the shortest route so that costs can be minimized. The aim of the research was to determine the shortest path in distributing goods in the Medan area to the location of consumers. The research used Ant Colony Optimization (ACO). Determination of the shortest path is based on distance calculations in kilometers, protocol roads, gangs, normal road conditions, and differences between small and major roads. Based on the research results, it is found that the J1 line has the greatest value. So, the path chosen by the ants to pass is $\mathrm{J} 1$ which is $11 \mathrm{~km}$ away from the departure location (PT Everbright) to the destination (Pasar Glugur Kota). It passes through PT Everbright $\rightarrow$ Jln. Gatot Subroto $\rightarrow$ Jln. Kapt. Muslim $\rightarrow$ Jln. Tgk. Amir Hamzah $\rightarrow$ Jln. KH. Syeikh Abdul Wahab Rokan $\rightarrow$ Pasar Glugur Kota.
\end{abstract}

Keywords: shortest path, Ant Colony Optimization (ACO), algorithm

\section{INTRODUCTION}

Distribution is a process that shows the distribution of goods from producers to reach widespread consumers (Tuani, Keedwell, \& Collett, 2020). Along with the times, the distribution process must be improved so that the companies can compete in the current era of globalization. Determination of the distribution channel of goods at companies as the distributor is constrained. Hence, it results in unachieved targets. This issue is the beginning of problems in the distribution of goods.

Moreover, the newly recruited drivers, especially those who do not come from the same area, encountered problems in distributing goods. The drivers do not know the shortest path to consumers' locations. It complicates delivery because there is more than one route to the customers' location.

The shortest path is a part of graph theory. Graphs are used to describe various kinds of existing structures, such as organizational structures, road routes, and course-taking flowcharts (Hinz \& Heide, 2014; Tuani et al., 2020). Several algorithms can be used to determine the shortest path in the distribution of goods. However, the problem of finding the shortest path in a graph is one of the optimization problems (Dzalbs \& Kalganova, 2020).

The solution to the search for the shortest path can be done using two methods, namely the conventional algorithm and the heuristic methods. The conventional method is an algorithm that uses ordinary mathematical calculations (Jha, Chen, \& Shima, 2020). Several conventional methods are commonly used to search the shortest path, including Djikstraa, Floyd-Warshall, and Bellman-Ford algorithms (Demir \& Erden, 2020).

Meanwhile, the heuristic method is a subfield of artificial intelligence to search and determine the shortest path (Baek, Lee, \& Eom, 2021). The heuristic method is applied by calculating artificial intelligence and determining the knowledge base and its calculations (Xin \& Wang, 2007). Several algorithms in the heuristic method are commonly used to find the shortest path (Liang, Kang, \& Fang, 2020). One of them is the Ant Colony Optimization (ACO) algorithm. The term shortest on the path problem means the process of minimizing the weight on a path 
in the graph (Lubiw, Maftuleac, \& Owen, 2020; Liu, Luo, Guo, \& Tan, 2020; Jha et al., 2020).

There are several problems with the shortest path. It includes the shortest path between two vertices, all pairs of vertices, a particular vertex to all other vertices, and two vertices through certain vertices (Zeng, Miwa, \& Morikawa, 2017). In solving problems about weighted graphs and a vertex, the research can determine the shortest cross from each vertex at $G$ (see Equation 1). It shows $G$ as graph, $V$ as vertices (nodes), and $E$ as edges (arcs). The assumption is that all edges are positive weight (see Figure 1).

$\mathrm{G}=(\mathrm{V}, \mathrm{E})$

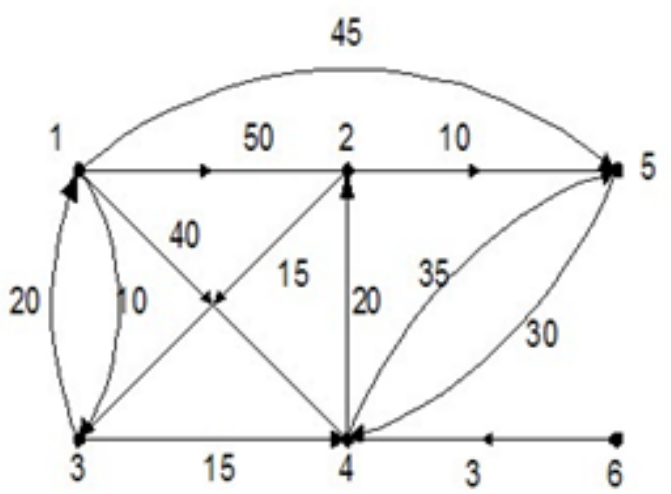

Figure 1 An Example Graph of the Shortest Path Problem (Source: Hinz \& Heide, 2014)

According to Figure 1, the settlement method of the shortest path is the ant algorithm. Dorigo and his friends first proposed the ant algorithm in 1996 as an initial approach to difficult problems, such as the Traveling Salesman Problem (TSP) and Quadratic Assignment Problem (QAP). The inspiration for the ant algorithm is built on by observing an actual ant colony. The ant algorithm, also known as an ant colony, is inspired by the ant's behavior to find food sources (Tuani et al., 2020). The use of the ant algorithm is based on the natural properties of the ants to choose or determine the shortest path from the ants' nest to the location of the food source (Wen, 2020). Ants are social insects that live in colonies or groups and have specific behavior to better maintain the colony's life as a whole rather than live as individuals (Tuani et al., 2020). Ants travel from food sources to their nest or vice versa. Then, the ants deposit a substance called pheromone on the ground. It forms a pheromone pathway, and the ants tend to choose that path (Lubiw et al., 2020; Tuani et al., 2020). Figure 2 shows the journey of ants to find a food source.

An ant colony can find the shortest path between a nest and a food source based on its traversed footprints. The more ants cross the path, the clearer the footprints will be (Jha et al., 2020; Zhang et al., 2020). This situation causes the paths traversed by ants in small numbers to be more numerous or denser. Even all ants will pass through that path. Figure 2a shows the journey of the ants in finding the shortest path from the nest to the food source. There are two groups of ants. The ants in group L depart from the left to the right, and the ants in group $\mathrm{R}$ go from the right to the left. The two groups depart from the same point and are in a position to decide which path to take. Group L is divided into two groups again. Some ants pass the upper road, and some pass the lower way (Pan et al., 2020; Patino-Ramirez, Layhee, \& Arson, 2020). This situation is also applied to group R. Figures $2 b$ and $2 c$ show that the ant group travels at the same speed leaving pheromones or footprints on the road that has been traversed. The pheromones left by the ants passing the upper road have experienced
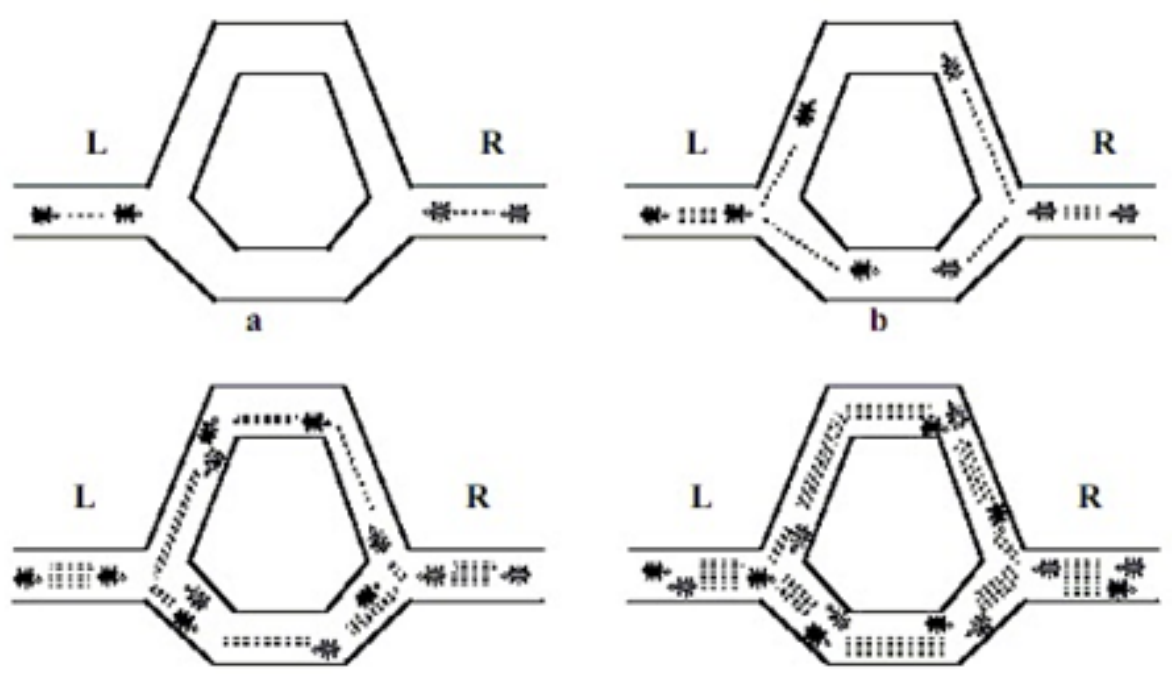

c

d

Figure 2 The Journey of Ants to Find Food Source

(Source: Gupta \& Srivastava, 2020) 
much evaporation because fewer ants pass the upper road than on the lower road. It is because the distance traveled is longer than the lower road. Meanwhile, the evaporation of pheromones in lower road tends to take longer. More ants pass through the lower road than the upper way.

Then, Figure 2d illustrates that the other ants finally decide to go through the lower path because there are still many pheromones left. The pheromones on the upper road have evaporated a lot, so the ants do not choose the upper path (Wen, 2020). The more ants pass the road, the more ants follow it. However, the fewer ants pass through the road, the fewer pheromones are left behind and will even disappear. Therefore, the shortest path between the nest and the food source is chosen (Maheshwari, Sharma, \& Verma, 2021; Miao, Zhang, Hu, \& Wang, 2020).

There are several studies regarding the shortest path. Rosa, Suhartono, and Wibawa (2013) used the path search method using the Branch and Bound algorithm based only on distance. Similarly, Dahni and Rahmiati (2017) discussed the shortest path using the ant algorithm. However, in determining and ordering the shortest path, they only used fire google maps. Then, Desiaman (2019) applied the Djikstra algorithm but still used google maps to see the shortest path. Soetomo (2018) also used the campus library (r) to the campus library (s) with ACO consisting of the input of origin and destination of the library and a graph that represented a point as a library.

Similar to Soetomo (2018) and Zhao et al., (2021), in the research, the campus library (r) to the campus library (s) also applies the ACO method. It is with input in the form of libraries as origin and destination. It also has a graph that represents a point as a campus library and a line or side as a connecting line.

The researcher intends to use the ant algorithm to determine the shortest path of distribution of goods and design an application that implements the ant algorithm based on Phanden, Sharma, Chhabra, and Demir (2021). Based on the description, several problems arise as adopted from Zhao, Zhang, and Zhang (2020): How to determine the shortest route of distribution of goods using the ACO at PT Everbright in Medan? How to design an application that applies ant algorithms in determining the shortest route of distribution of goods at PT Everbright in Medan? Moreover, the application design is limited to the departure location. It only starts from PT Everbright with three-lane choices, which are protocol lines, including alley. Then, the other assumptions are that the road conditions are considered normal, and lane distance determination is calculated only in kilometers. The aim is to determine the shortest path in distributing goods from PT Everbright to the consumers' location by using ACO and design an application that applies the ACO in determining the distribution route of goods in PT Everbright in Medan.

\section{METHODS}

The steps of the ant algorithm for determining the shortest path are adopted from Xin and Wang (2007). The first stage initializes the value of the parameters, the number of nodes $(n)$ along with the coordinates $(x, y)$ or the distance between the nodes $(d)$, the intensity of the ant trails between nodes $(\tau i j)$, the ant-cycle constant $(Q)$, the ant trail intensity control constant $(\alpha)$, the visibility control constant $(\beta)$, the visibility between nodes of $1 / d \eta(\eta i j)$, the number of ants $(m)$, the ant trail evaporation constant $(\rho)$, and the maximum number of cycles (NCmax) (Guan, Zhao, \& $\mathrm{Li}, 2021)$. The second stage arranges the visited path for each ant. The probability equation for the node to be visited is used to determine the destination node, as seen in Equation (2) (Liang et al., 2020).

$$
P_{i j}^{k}=\frac{\left[\tau_{\mathrm{ij}}\right]^{\alpha}\left[\eta_{i j}\right]^{\beta}}{\sum_{k^{\prime} \in\left[\mathrm{N}-\mathrm{tabu}_{\mathrm{k}}\right.}\left[\tau_{i k}\right]^{\alpha}\left[\eta_{i k}\right]^{\beta}}
$$

Then, $j \in\left\{N-t a b u_{k}\right\}$ is for another $\mathrm{j}$. It shows that $i$ as the index of the departure node, and $j$ as the index of the destination. Then, the largest probability value is chosen as the destination node by the ant. So, the result is $P_{i j}^{k}=0$.

The third stage calculates the length of the path $(L k)$ for each ant. It is done after one cycle is completed by all the ants (Kumar, Singh, \& Ashfaq, 2020). The calculation is done with Equation (3).

$$
L_{k}=d_{t a b u_{k}(n), t a b u_{k}(1)}+\sum_{s=1}^{n-1} d_{t a b u_{k}}
$$

It shows $(s), t_{a b u}(s+1)$ where $d i j$ is the distance between node $i$ to node. It determines the shortest path $(\operatorname{Lmin} N C)$.

The fourth stage is the calculation of changes in the intensity value of ants' footprints between nodes. It uses Equation (4). Then, the change in the intensity value of the ant footprints between nodes of each ant is calculated based on Equation (5).

$$
\begin{aligned}
& \Delta \tau_{i j}=\sum_{k=1}^{m} \Delta \tau_{i j}^{k} \\
& \Delta \tau_{i j}^{k}=\frac{Q}{L_{k}}
\end{aligned}
$$

There is $(i, j) \in$ origin node and a destination node in tab for $(\mathrm{i}, \mathrm{j})$. So, the result is $\Delta \tau_{i j}^{k}=0$.

The fifth stage is a calculation of the intensity value of ants' footprints between nodes for the next cycle using Equation (6). It resets the value for the 
change in the intensity of the ants' footprints between nodes. The sixth stage empties the taboo list and returns to the second stage if it is necessary. The taboo list must be left empty to be filled again with the sequence of new nodes in the next cycle if the maximum number of cycles has not been reached (Tuani et al., 2020).

$$
\tau_{i j}=\rho \cdot \tau_{i j}+\Delta \tau_{i j}
$$

A clearer and more detailed research framework is needed to solve the shortestpath with the antalgorithm. The research framework for data collection is shown in Figure 3. There are three core stages in completing this research. The first part is reading literature related to topics in the latest journals, reference books, and other scientific references. After that, the researcher will identify the problem from the weaknesses in the reading material like previous journals or researchers. Then, the researcher formulates the problem and sets the research objectives, which are certainly related to the case study to be resolved. The second part is data collection and analysis, applying the ant algorithm method to determine the shortest path. Then, based on the results using the method, the researcher will build a system that can automatically determine the shortest path by adopting the ant algorithm. In the third part, the researcher will validate the data from the analysis and simulation of the built system. After the simulation, there will be system testing stages. Next, the researcher can conclude whether the system is successful or not. If it is successful, the system is ready to use, and conclusions will emerge in the discussion. However, if it does not work, it will return to the second stage until it works and finishes.

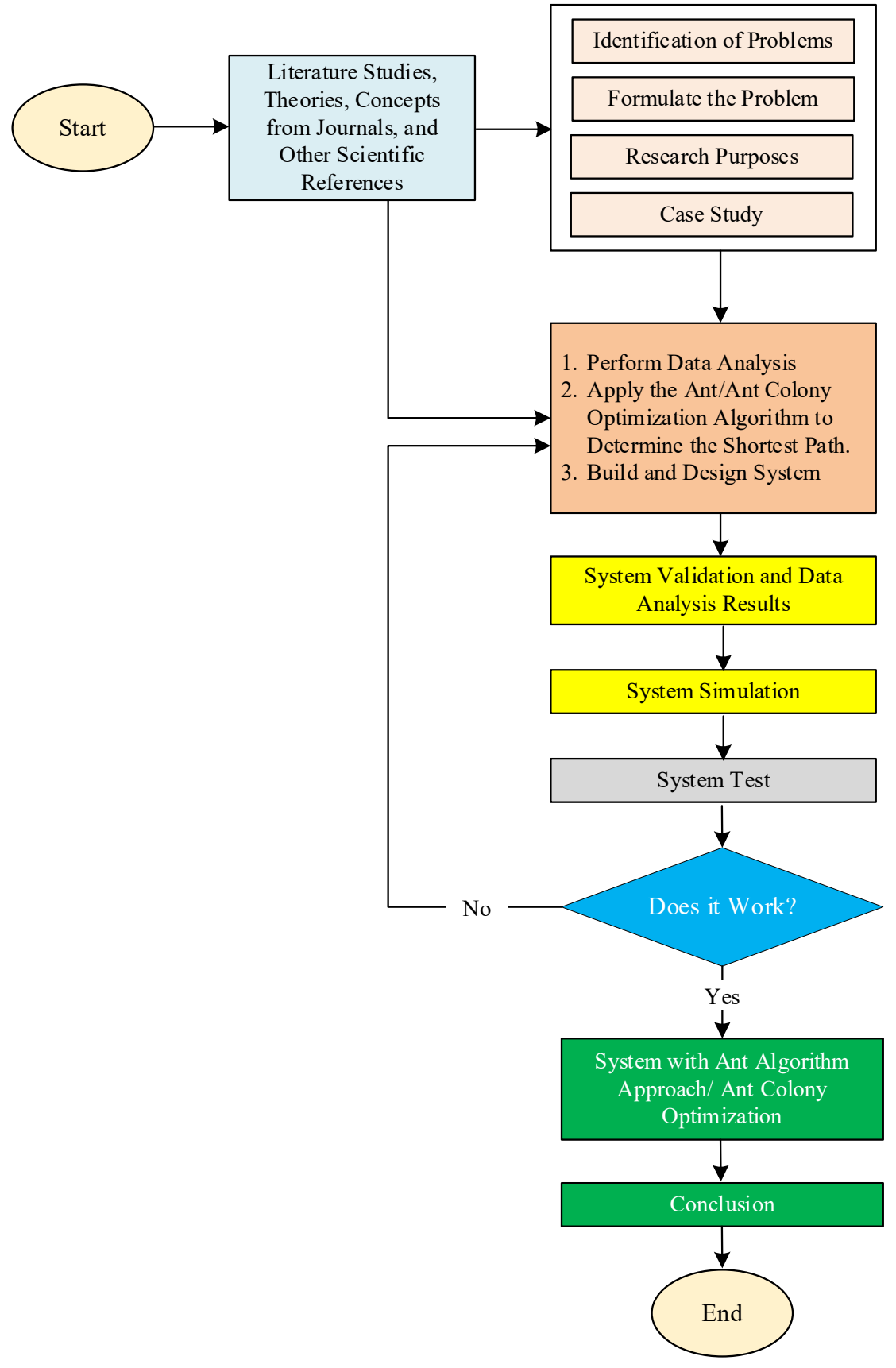

Figure 3 Research Flow 


\section{RESULTS AND DISCUSSIONS}

The use of the ant algorithm in determining the shortest path in the application can be calculated using an example of a case (see Figure 4). The calculation is carried out with only one departure location, PT Everbright. Therefore, the number of cycles and ants in the ant algorithm used is also one.

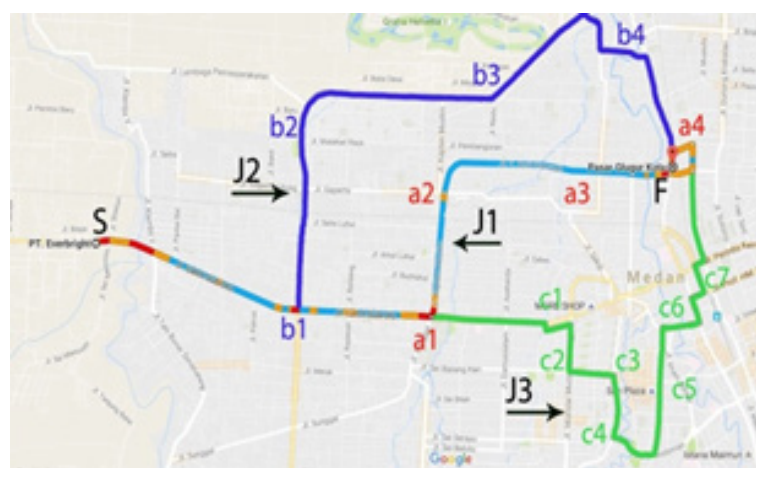

Figure 4 The Example of the Case

In Figure 4, there are several indicators. S is PT Everbright as the departure location, and $\mathrm{F}$ is Pasar Glugur Kota as the destination. Then, J1 is the first route formed to S1. Meanwhile, $\mathrm{J} 2$ is the second route formed to $\mathrm{S} 1$, and $\mathrm{J} 3$ is the third route formed to $\mathrm{S} 1$. To determine the shortest path from the path of Figure 2 , the researcher uses the parameter values of $0,1(\tau i j)$, $1(n), 1(m), 1(Q), 1(\alpha)$, and $1(\beta)$.

Table 1 The Name of the Roads

\begin{tabular}{ccl}
\hline No. & Code & Name \\
\hline 1 & S & PT Everbright \\
2 & a1 & Jalan Gatot Subroto \\
3 & a2 & Jalan Kapten Muslim \\
4 & a3 & Jalan T. Amir Hamzah \\
5 & a4 & Jalan.KH.Syeikh Abdul Wahab \\
& & Rokan \\
6 & b1 & Jalan Gatot Subroto \\
7 & b2 & Jalan Asrama \\
8 & b3 & Jalan Kapten Sumarsono \\
9 & b4 & Jalan J1. Karya Cilincing \\
10 & c1 & Jalan Gatot Subroto \\
11 & c2 & Jalan Iskandar Muda \\
12 & c3 & Jalan Gajah Mada \\
13 & c4 & Jalan Siswondo Parman \\
14 & c5 & Jalan Pangeran Dipenogoro \\
15 & c6 & Jalan Kapten Maulana Lubis \\
16 & c7 & Jalan Gaharu \\
17 & F & Pasar Glugur Kota \\
\hline
\end{tabular}

Table 2 The Road Distance of Line 1

\begin{tabular}{cc}
\hline Passed Path & Distance (km) \\
\hline $\mathrm{S} \rightarrow \mathrm{a} 1$ & 4,9 \\
$\mathrm{a} 1 \rightarrow \mathrm{a} 2$ & 1,6 \\
$\mathrm{a} 2 \rightarrow \mathrm{a} 3$ & 2,9 \\
$\mathrm{a} 3 \rightarrow \mathrm{a} 4$ & 1,42 \\
$\mathrm{a} 4 \rightarrow \mathrm{F}$ & 0,18 \\
\hline
\end{tabular}

Table 3 The Road Distance of Line 2

\begin{tabular}{cc}
\hline Passed Path & Distance $(\mathbf{k m})$ \\
\hline $\mathrm{S} \rightarrow \mathrm{b} 1$ & 3 \\
$\mathrm{~b} 1 \rightarrow \mathrm{b} 2$ & 3,1 \\
$\mathrm{~b} 2 \rightarrow \mathrm{b} 3$ & 3,4 \\
$\mathrm{~b} 3 \rightarrow \mathrm{b} 4$ & 1,6 \\
$\mathrm{~b} 4 \rightarrow \mathrm{F}$ & 1,5 \\
\hline
\end{tabular}

Table 4 The Road Distance of Line 3

\begin{tabular}{cc}
\hline Passed Path & Distance $(\mathbf{k m})$ \\
\hline $\mathrm{S} \rightarrow \mathrm{c} 1$ & 7,55 \\
$\mathrm{c} 1 \rightarrow \mathrm{c} 2$ & 0,6 \\
$\mathrm{c} 2 \rightarrow \mathrm{c} 3$ & 0,65 \\
$\mathrm{c} 3 \rightarrow \mathrm{c} 4$ & 0,8 \\
$\mathrm{c} 4 \rightarrow \mathrm{c} 5$ & 1,6 \\
$\mathrm{c} 5 \rightarrow \mathrm{c} 6$ & 0,52 \\
$\mathrm{c} 6 \rightarrow \mathrm{c} 7$ & 1 \\
$\mathrm{c} 7 \rightarrow \mathrm{F}$ & 1,98 \\
\hline
\end{tabular}

From Tables 1-4, the length of the closed tour ( $L k$ ) can be calculated. By using Equation (2), the following results are obtained. The calculation result for $\mathrm{J} 1$ is $11 \mathrm{~km}$. Then, J2 is $12,6 \mathrm{~km}$, and J3 is 14,7 $\mathrm{km}$. From $\mathrm{J} 1, \mathrm{~J} 2$, and $\mathrm{J} 3$, the shortest path will be determined using Equation (3). The calculation results will be obtained as follows:

$$
\begin{aligned}
& \operatorname{Lmin} N C=\operatorname{Min}(\operatorname{Lj} 1, \operatorname{Lj} 2, \operatorname{Lj} 3) \\
& \operatorname{Lmin} N C=\operatorname{Min}(11,12,6,14,7) \\
& \operatorname{Lmin}=11 \mathrm{~km}
\end{aligned}
$$

To determine which path the ants choose from the formed path, the researchers use Equation (4). The calculation result for $\mathrm{Pj} 1$ is $0,38161, \mathrm{Pj} 2$ is 0,033291 , and $\mathrm{Pj} 3$ is 0,28547 . From the results, it can be concluded that Pj1 will be chosen as the shortest path because it is closer to the optimal number, 1 .

From the results of the calculations, the J1 line has the greatest value. So, the path chosen by the 
ants to pass is $\mathrm{J} 1$ which is $11 \mathrm{~km}$. For changes in the intensity value of ant footprints (new $\Delta \tau i j$ and $\tau i j$ ), it is not necessary to be calculated because the equation is only used for more than one cycle. Then the shortest path from Figure 4 is the J1 line that passes through PT Everbright $\rightarrow$ Jl. Gatot Subroto $\rightarrow$ Jl. Kapten Muslim $\rightarrow$ Jl. T. Amir Hamzah $\rightarrow$ Jl. KH.Syeikh Abdul Wahab Rokan $\rightarrow$ Pasar Glugur Kota.

After discussing the case studies that have been determined, the researcher process the results into the application system. The application consists of several forms. The existing forms have their respective functions. First, there is a location selection form. The destination locations will appear, and the admin can choose one of the locations to determine the shortest path. The location is selected by choosing one of the listed checkboxes. If the destination location is wrong, the user can press the cancel button and select the destination location again. Then, the user can select the button of viewing the map to view the shortest path that has been determined. Figure 5 (see Appendices) displays this function

Second, in the map view form, the shortest path is selected from the calculated path determination. It shows the shortest path from the departure location (PT Everbright) to the destination. It is shown in Figure 6 (see Appendices).

Third, Figure 7 (see Appendices) displays the path determination menu form. In this menu, the three paths are formed along with the names of the traversed roads. Each existing path appears on the left side of the menu.

In the same form, the probability of selecting the path chosen by the ant can be calculated by entering $\alpha$ and $\beta$ values in the textbox. After entering the values, the user presses the process button next to the $\tau i j$ textbox. After processing the data, the results of the probability calculation will appear according to the equation used in the ant algorithm. From the three probability results, the path chosen by ants will appear based on the largest value in the existing path probability value. The display of this menu is in Figure 8 (see Appendices).

After calculating the probability of selecting the path chosen by the ants is obtained, the shortest path can be determined based on the length of the path from the three existing paths by determining the L min of the three path distances. To find L min, the user presses the process button in the row in the calculation of probability value. Then, the path length will appear from the total distance between the roads passed on each path. Automatically, the Lmin value will be obtained, which is the shortest path. After that, the user can press the save button to save the results into the database and print them. Figure 9 (see Appendices) shows the determination of the shortest path.

Fourth, Figure 10 (see Appendices) displays the path print menu. To print the shortest path that has been saved, the user can select or click data on the data grid view. After pressing the print button, it displays the results of the report to be printed. When the exit button is pressed, the print path menu will close and return to the main menu.

Fifth, there are report results. After the results from determining the saved shortest path are printed, it looks like the report in Figure 11 (see Appendices). It shows the Logo of PT Everbright on the top left and company data on the right as head of the report. The body will display the departure location, destination location, path selected by ants, the length of the distance from the selected path as the shortest path, and the paths taken according to the selected path.

\section{CONCLUSIONS}

Based on the analysis and the results of the discussion, there are several conclusions. First, the $\mathrm{J} 1$ line has the greatest value, so the path that the ants choose to pass is $\mathrm{J} 1$ which is $11 \mathrm{~km}$. Second, the changes in the intensity value of ants' footprints (new $\Delta \tau i j$ and $\tau i j$ ) are not necessary to be calculated because the equation is only used for more than one cycle. Third, the shortest path from Figure 4 is the J1 line that passes through PT Everbright $\rightarrow$ Jln. Gatot Subroto $\rightarrow$ Jln. Kapten Muslim $\rightarrow$ Jln. T. Amir Hamzah $\rightarrow$ Jln. KH. Syeikh Abdul Wahab Rokan $\rightarrow$ Pasar Glugur Kota. Thus, the optimization solution regarding determining the shortest path can be done using the ACO or ant algorithm approach.

Further research can be continued using realtime applications. Thus, it can show current conditions and the right time count. It will show not only the shortest path but also time calculation. Other than the protocol roads, future research can also use small roads.

\section{REFERENCES}

Baek, S. G., Lee, S., \& Eom, Y. I. (2021). Efficient singlepair all-shortest-path query processing for massive dynamic networks. Information Sciences, 546, 13061327. https://doi.org/10.1016/j.ins.2020.08.111

Dahni, Y. S., \& Rahmiati. (2017). Sistem informasi penentuan jalur terpendek bagi pengantar surat menggunakan algoritma semut. Jurnal INOVTEK Polbeng - Seri Informatika, 2(2), 148-160. https:// doi.org/10.35314/isi.v2i2.202

Demir, H. I., \& Erden, C. (2020). Dynamic integrated process planning, scheduling and due-date assignment using ant colony optimization. Computers \& Industrial Engineering, 149(November), 1-12 https://doi. org/10.1016/j.cie.2020.106799

Desiaman, D. (2019). Penentuan jalur terpendek dengan menggunakan algoritma Djikstra dalam pencarian kost di Kota Medan. KAKIFIKOM (Kumpulan Artikel Karya Ilmiah Fakultas Ilmu Komputer), 1(1), $1-5$.

Dzalbs, I., \& Kalganova, T. (2020). Accelerating supply chains with ant colony optimization across a range of hardware solutions. Computers \& Industrial 
Engineering, 147(September), 1-14. https://doi. org/10.1016/j.cie.2020.106610

Guan, B., Zhao, Y., \& Li, Y. (2021). An improved ant colony optimization with an automatic updating mechanism for constraint satisfaction problems. Expert Systems with Applications, 164(February), 1-7. https://doi. org/10.1016/j.eswa.2020.114021

Gupta, A., \& Srivastava, S. (2020). Comparative analysis of ant colony and particle swarm optimization algorithms for distance optimization. Procedia Computer Science, 173, 245-253. https://doi. org/10.1016/j.procs.2020.06.029

Hinz, A. M., \& Heide, C. H. A. D. (2014). An efficient algorithm to determine all shortest paths in Sierpiński graphs. Discrete Applied Mathematics, 177, 111120. https://doi.org/10.1016/j.dam.2014.05.049

Jha, B., Chen, Z., \& Shima, T. (2020). On shortest Dubins path via a circular boundary. Automatica, 121(November), 1-9. https://doi.org/10.1016/j. automatica.2020.109192

Kumar, R., Singh, R., \& Ashfaq, H. (2020). Stability enhancement of multi-machine power systems using ant colony optimization-based static synchronous compensator. Computers \& Electrical Engineering, 83(May), 1-17. https://doi.org/10.1016/j. compeleceng.2020.106589

Liang, F., Kang, C., \& Fang, F. (2020). A smooth tool path planning method on NURBS surface based on the shortest boundary geodesic map. Journal of Manufacturing Processes, 58(October), 646-658. https://doi.org/10.1016/j.jmapro.2020.08.047

Liu, L., Luo, S., Guo, F., \& Tan, S. (2020). Multi-point shortest path planning based on an improved discrete bat algorithm. Applied Soft Computing, 95(October), 1-10. https://doi.org/10.1016/j.asoc.2020.106498

Lubiw, A., Maftuleac, D., \& Owen, M. (2020). Shortest paths and convex hulls in 2D complexes with non-positive curvature. Computational Geometry, 89(August), 1-24. https://doi.org/10.1016/j.comgeo.2020.101626

Maheshwari, P., Sharma, A. K., \& Verma, K. (2021). Energy efficient cluster based routing protocol for WSN using butterfly optimization algorithm and ant colony optimization. Ad Hoc Networks, 110. https:// doi.org/10.1016/j.adhoc.2020.102317

Miao, M., Zhang, W., Hu, W., \& Wang, R. (2020). An adaptive multi-domain feature joint optimization framework based on composite kernels and ant colony optimization for motor imagery EEG classification. Biomedical Signal Processing and Control, 61(August), 1-15. https://doi.org/10.1016/j. bspc. 2020.101994

Pan, M., Li, C., Gao, R., Huang, Y., You, H., Gu, T., \& Qin, F. (2020). Photovoltaic power forecasting based on a support vector machine with improved ant colony optimization. Journal of Cleaner Production, 277, 1-12. https://doi.org/10.1016/j.jclepro.2020.123948

Patino-Ramirez, F., Layhee, C., \& Arson, C. (2020). Horizontal Directional Drilling (HDD) alignment optimization using ant colony optimization.
Tunnelling and Underground Space Technology, 103(September), 1-13. https://doi.org/10.1016/j. tust.2020.103450

Phanden, R. K., Sharma, L., Chhabra, J., \& Demir, H. İ. (2021). A novel modified ant colony optimization based maximum power point tracking controller for photovoltaic systems. Materials Today: Proceedings, 38, 89-93. https://doi.org/10.1016/j. matpr.2020.06.020

Rosa, W. R., Suhartono, S., \& Wibawa, H. A. (2013). Penentuan jalur terpendek pada pelayanan agen travel khusus pengantaran wilayah Semarang berbasis SIG dengan algoritma branch and bound. Jurnal Masyarakat Informatika, 4(7), 9-14. https:// doi.org/10.14710/jmasif.4.7.9-14

Soetomo, C.A. L. (2018). Penentuan jalur terpendek dengan menggunakan metode ant colony optimization (Undergraduate Thesis). Universitas Islam Negeri Maulana Malik Ibrahim.

Tuani, A. F., Keedwell, E., \& Collett, M. (2020). Heterogenous adaptive ant colony optimization with 3-opt local search for the travelling salesman problem. Applied Soft Computing, 97, 1-14. https:// doi.org/10.1016/j.asoc.2020.106720

Wen, X. (2020). Modeling and performance evaluation of wind turbine based on ant colony optimizationextreme learning machine. Applied Soft Computing, 94(September). $\quad \mathrm{https} / /$ doi.org/10.1016/j. asoc. 2020.106476

Xin, S. Q., \& Wang, G. J. (2007). Efficiently determining a locally exact shortest path on polyhedral surfaces. Computer-Aided Design, 39(12), 1081-1090. https:// doi.org/10.1016/j.cad.2007.08.001

Zeng, W., Miwa, T., \& Morikawa, T. (2017). Application of the support vector machine and heuristic k-shortest path algorithm to determine the most eco-friendly path with a travel time constraint. Transportation Research Part D: Transport and Environment, 57(December), 458-473. https://doi.org/10.1016/j. trd.2017.10.001

Zhang, T., Cheng, Y., Wu, H., Song, Y., Yan, S., Handroos, H., Zheng, L., Ji, H., \& Pan, H. (2020). Dynamic Accuracy Ant Colony Optimization of Inverse Kinematic (DAACOIK) analysis of Multi-Purpose Deployer (MPD) for CFETR remote handling. Fusion Engineering and Design, 156(July), 1-9. https://doi.org/10.1016/j.fusengdes.2020.111522

Zhao, D., Liu, L., Yu, F., Heidari, A. A., Wang, M., Oliva, D., Muhammad, K., \& Chen, H. (2021). Ant colony optimization with horizontal and vertical crossover search: Fundamental visions for multithreshold image segmentation. Expert Systems with Applications, 167. https://doi.org/10.1016/j. eswa.2020.114122

Zhao, H., Zhang, C., \& Zhang, B. (2020). A decompositionbased many-objective ant colony optimization algorithm with adaptive reference points. Information Sciences, 540(November), 435-448. https://doi.org/10.1016/j.ins.2020.06.028 


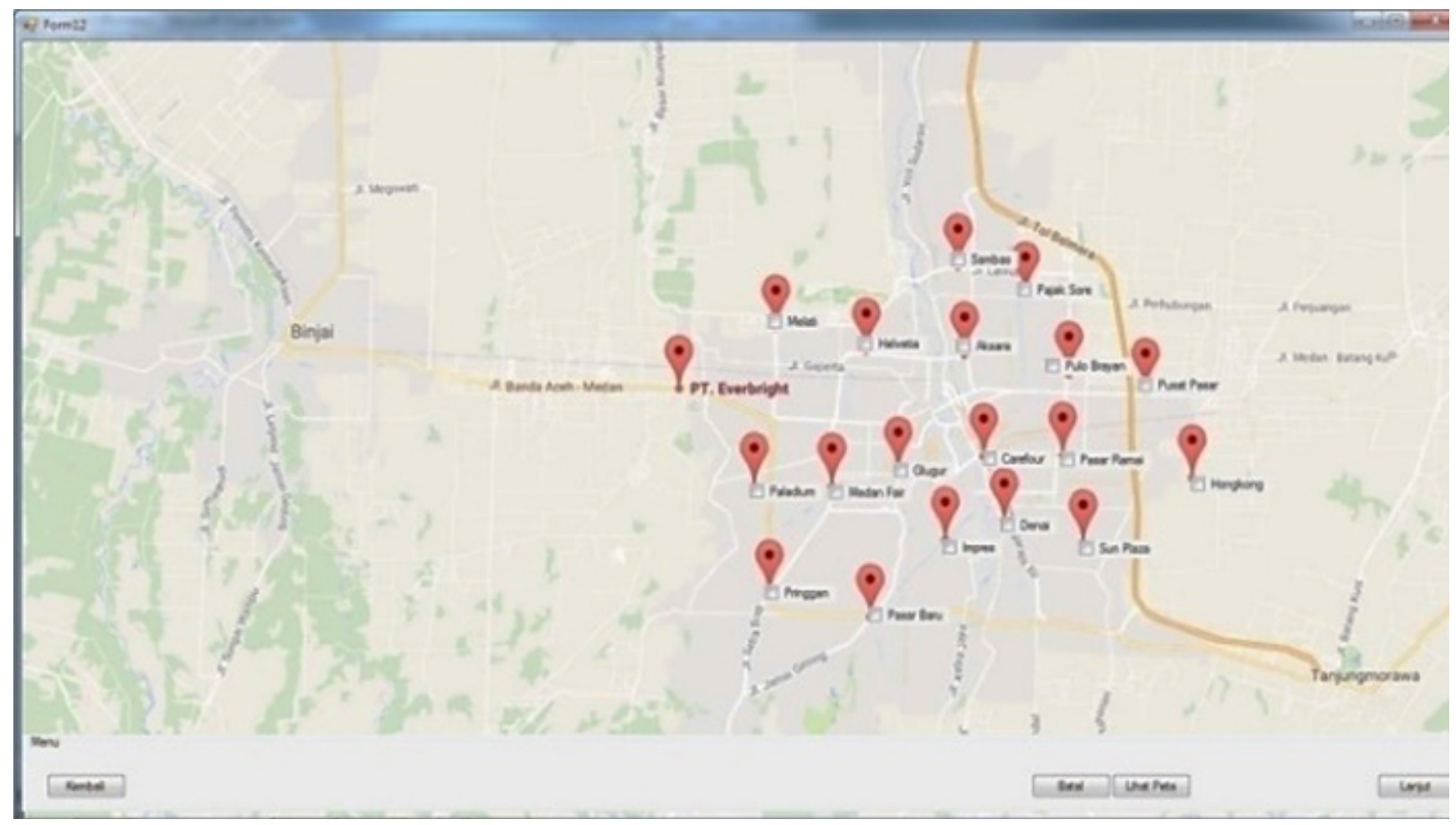

Figure 5 Location Selection Form

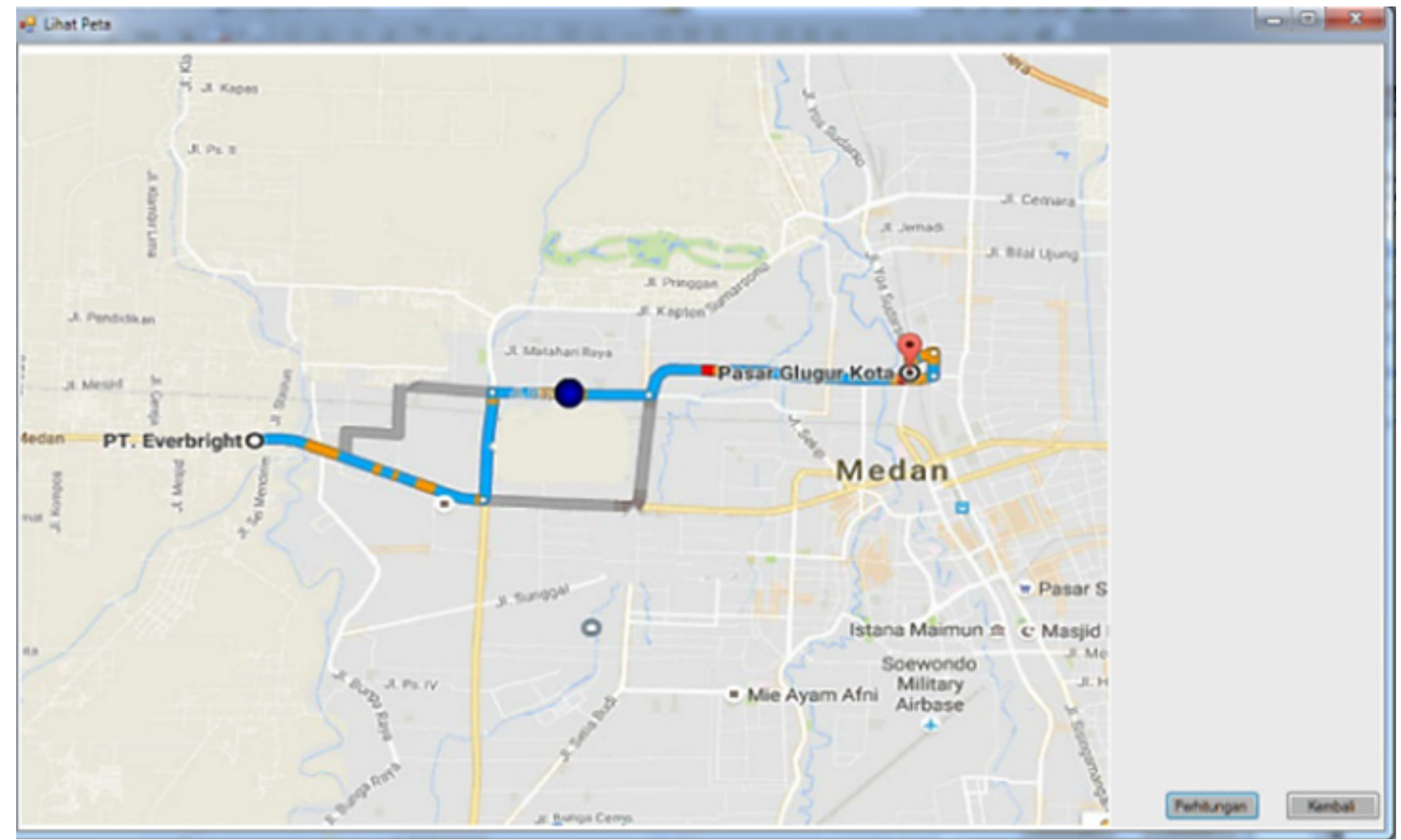

Figure 6 Map View Form 


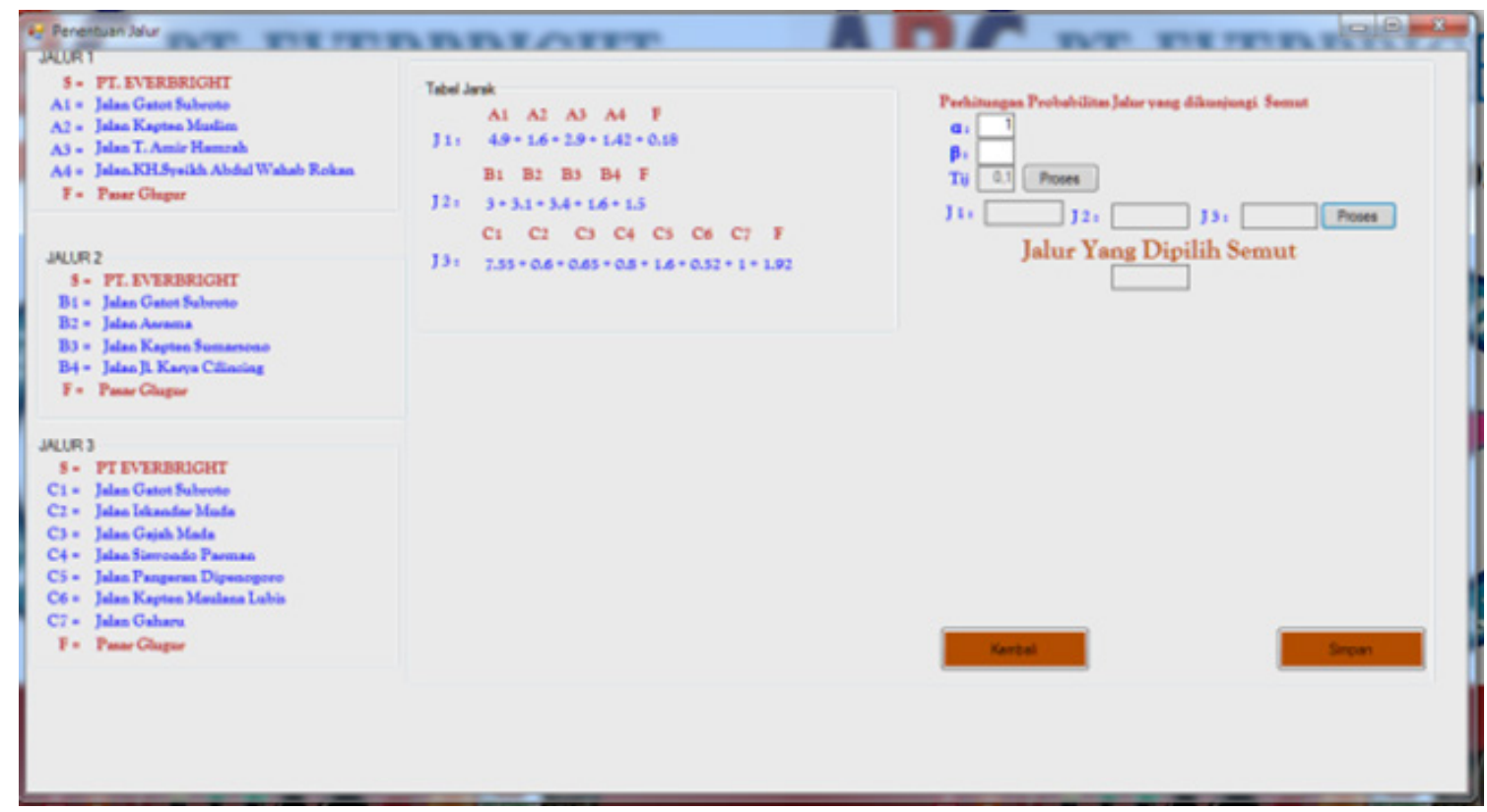

Figure 7 Line Determination Menu Form

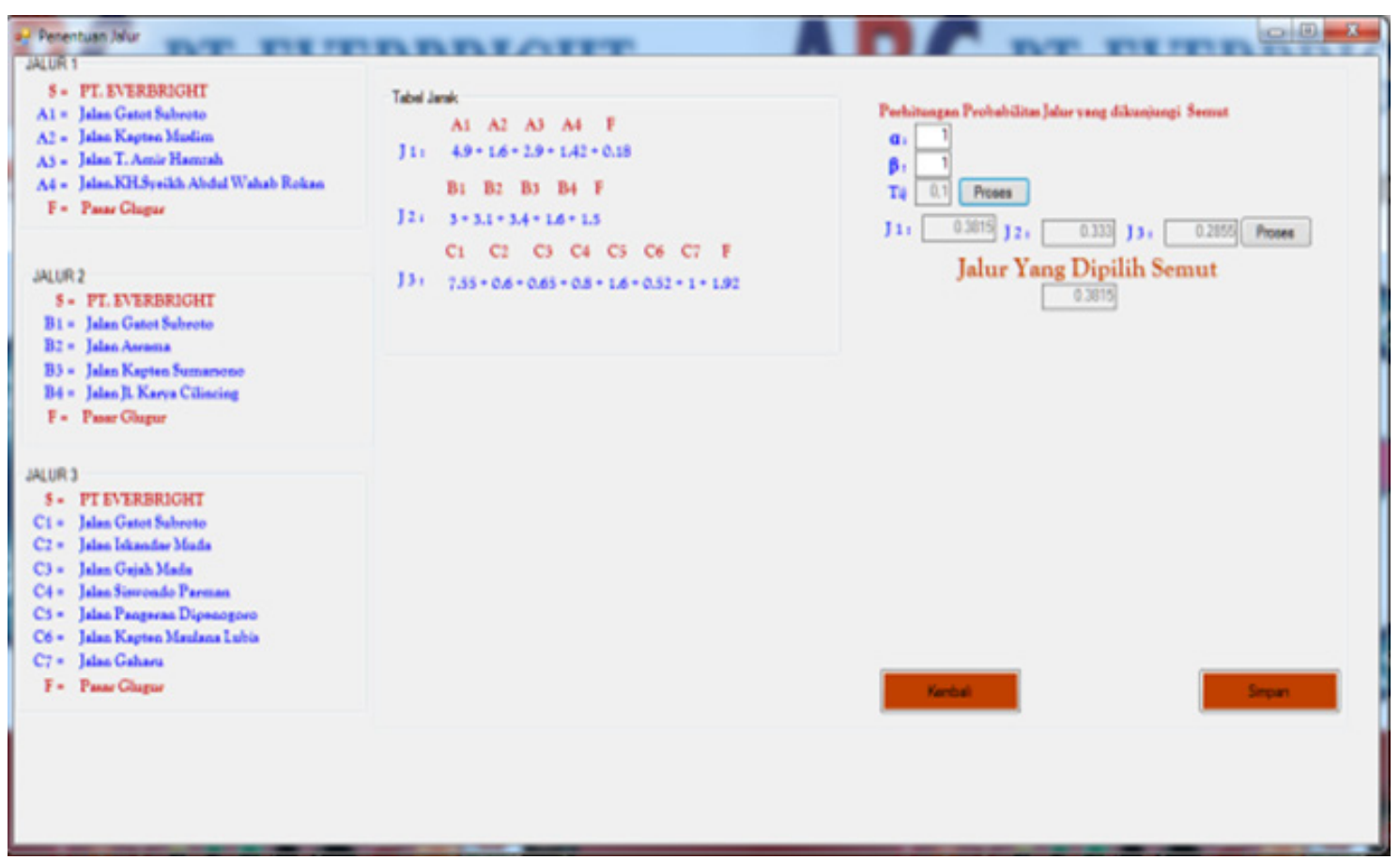

Figure 8 Calculation of the Probability in Selecting the Path that Ants Choose 


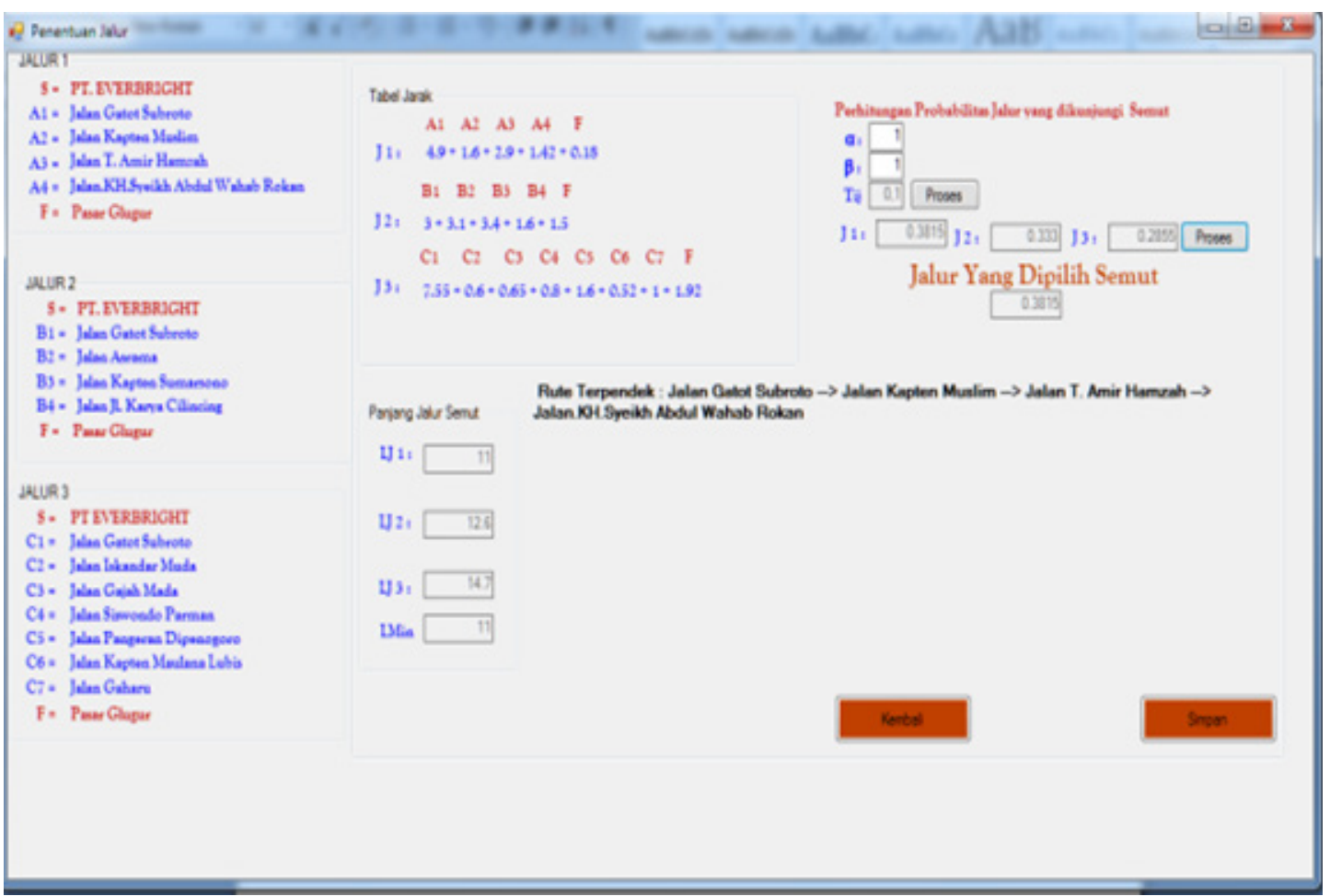

Figure 9 Determination of the Shortest Path

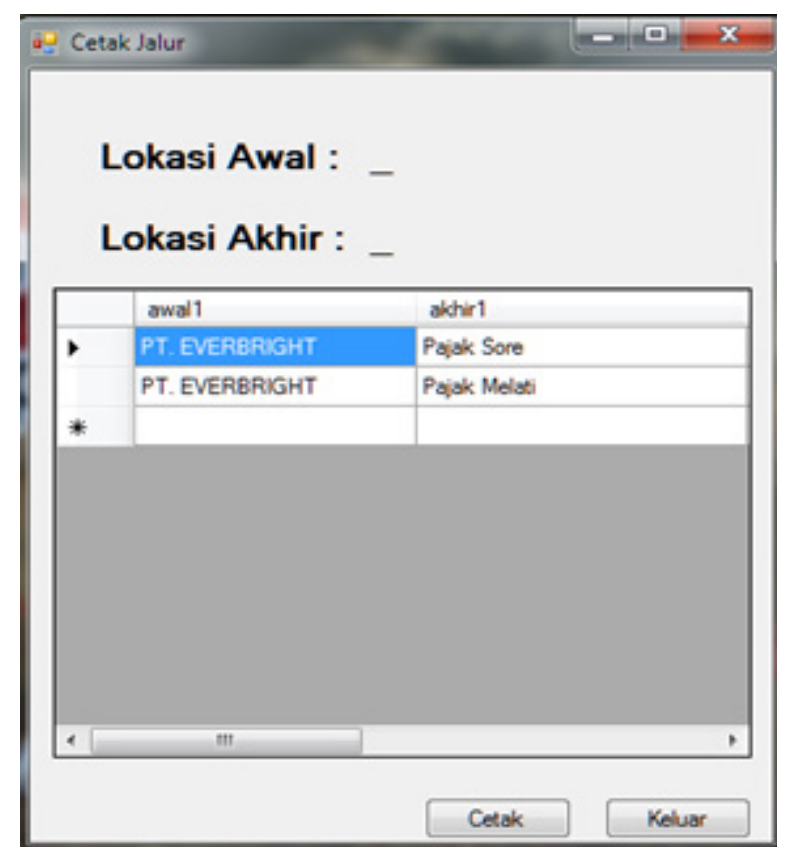

Figure 10 Path Print Menu 
$11 / 4 / 2016$

Titik keberangkatan : PT. EVERBRIGHT

Titik Akhir / Tujuan : Pajak Sore

Panjang Jarak $\quad: 9.6$

Nilai Probabilitas $\quad: 0.3484$

RUTE KEBERANGKATAN

Rute Terpendek: Jln. Gatot Subroto --> Jl. Kasuari --> Jln. Setia Budi --> Jln. Sei Serayu --> Jln. K. H.

Wahid Hasyim --> Jln. Jamin Ginting

Figure 11 Report Results.

In the figure, it states departure point (titik keberangkatan), last point or destination (titik akhir/tujuan), length (panjang jarak), probability value (nilai probabilitas), departure route (rute keberangkatan), and the shortest route (rute terpendek). 